\title{
Article
}

\section{Tunable Transparency and NIR-Shielding Properties of Nanocrystalline Sodium Tungsten Bronzes}

\author{
Luomeng Chao ${ }^{1} \mathbb{1}$, Changwei Sun ${ }^{1}$, Jianyong Dou ${ }^{1}$, Jiaxin $\mathrm{Li}^{1}{ }^{1}, \mathrm{Jia}$ Liu ${ }^{1}$, Yonghong Ma ${ }^{1, *}$ and Lihua Xiao ${ }^{2, *}$ \\ 1 College of Science, Inner Mongolia University of Science and Technology, Baotou 014010, China; \\ 2017993@imust.edu.cn (L.C.); $18722419110 @ 163 . c o m$ (C.S.); djyylw1880724@163.com (J.D.); \\ ljx19970319@163.com (J.L.); jialiu@imust.edu.cn (J.L.) \\ 2 Guizhou Institute of Technology, Guiyang 550003, China \\ * Correspondence: myh_dlut@126.com (Y.M.); xiaolihua@git.edu.cn (L.X.)
}

check for updates

Citation: Chao, L.; Sun, C.; Dou, J.;

Li, J.; Liu, J.; Ma, Y.; Xiao, L. Tunable Transparency and NIR-Shielding Properties of Nanocrystalline Sodium Tungsten Bronzes. Nanomaterials 2021, 11, 731. https://doi.org/10.3390/ nano11030731

Academic Editor: Matthieu Roussey

Received: 17 February 2021

Accepted: 12 March 2021

Published: 14 March 2021

Publisher's Note: MDPI stays neutral with regard to jurisdictional claims in published maps and institutional affiliations.

\begin{abstract}
The $\mathrm{Na}_{x} \mathrm{WO}_{3}$ nanoparticles with different $x$ were synthesized by a solvothermal method and the absorption behavior in visible and near-infrared light (NIR) region was studied. Wellcrystallized nanoparticles with sizes of several tens of nanometers were confirmed by XRD, SEM and TEM methods. The absorption valley in visible region shifted from $555 \mathrm{~nm}$ to $514 \mathrm{~nm}$ and the corresponding absorption peak in NIR region shifted from $1733 \mathrm{~nm}$ to $1498 \mathrm{~nm}$ with the increasing $\mathrm{x}$. In addition, the extinction behavior of $\mathrm{Na}_{x} \mathrm{WO}_{3}$ nanoparticles with higher $x$ values were simulated by discrete dipole approximation method and results showed that the changing behavior of optical properties was in good agreement with the experimental results. The experimental and theoretical data indicate that the transparency and NIR-shielding properties of $\mathrm{Na}_{x} \mathrm{WO}_{3}$ nanoparticles in the visible and NIR region can be continuously adjusted by $x$ value in the whole range of $0<x<1$. These tunable optical properties of nanocrystalline $\mathrm{Na}_{x} \mathrm{WO}_{3}$ will expand its application in the fields of transparent heat-shielding materials or optical filters.
\end{abstract}

Keywords: sodium tungsten bronzes; nanoparticles; tunable optical properties

\section{Introduction}

Tungsten bronze is a kind of solid solution formed by other cations filling in the lattice structure of $\mathrm{WO}_{3}$. Its chemical formula can be written as $\mathrm{M}_{x} \mathrm{WO}_{3}$, in which $\mathrm{M}$ is dopant cation and the $x$ value can vary in a certain range $(0<x<1, M$ is typically electropositive metals such as alkali, alkaline earth or rare-earth metals), which are non-stoichiometric compounds. The dopant $\mathrm{M}$ cation can contribute a number of electrons to reduce part of the hexavalent tungsten to pentavalent, which makes tungsten bronzes have special physical and chemical properties such as superconductivity [1], photochromism [2], electrochromism [3], photothermal conversion [4] and transparent heat-shielding properties [5], etc. Among these properties, the transparent heat-shielding properties have been studied extensively in recent years because the tungsten bronze exhibits low absorption of visible light and high absorption of near-infrared light (NIR), which meets the demand of smart windows with high visible transmittance and heat-shielding performance. The free electrons in tungsten bronzes can be regarded as the electron gas moving under the background of uniform positive charge (actually a kind of plasma). The plasma may resonate when it meets the incident light, while the plasma resonance frequency increases with the increase of carrier concentration and moves to the short-wave direction.

Tungsten bronzes have three types of cubic, tetragonal and hexagonal phases [5], and the tunnels formed by the $\mathrm{WO}_{6}$ octahedra with different phases are also different. The cubic phase contains only one type of cubic cavity, while the tetragonal phase contains not only tetragonal, but also tripartite and pentagonal channels. The hexagonal structure, which has been widely studied, contains tripartite and hexagonal channels. The size of dopant cation $\mathrm{M}$ determines the content and position of $\mathrm{M}$ in the structure of tungsten bronze. $\mathrm{H}^{+}$ 
and smaller alkali metal ions (such as $\mathrm{Li}^{+}$) can locate in the narrow tripartite channel, while larger alkali metal ions (such as $\mathrm{K}^{+}, \mathrm{Cs}^{+}$) or $\mathrm{NH}^{4+}$ can only locate in the hexagonal channel. If the dopant cation occupies all the hexagonal channels, then $x=0.33$. Among the various $\mathrm{M}_{x} \mathrm{WO}_{3}$, many studies indicate that $\mathrm{Na}_{x} \mathrm{WO}_{3}$ is the only compound which is possible to be synthesized in the wide range of $0<x<1$ [6-8], so it has become the most studied tungsten bronze. The electrical and optical properties of $\mathrm{Na}_{x} \mathrm{WO}_{3}$ can substantially change with varying $\mathrm{Na}$ content. When $x<\sim 0.2, \mathrm{Na}_{x} \mathrm{WO}_{3}$ exhibits semiconductor properties, and the electrical conductivity increases with increasing $x$ and thus $\mathrm{Na}_{x} \mathrm{WO}_{3}$ shows metallic properties at high $x$ [9]. Moreover, the changing electrical conductivity also leads to changing color in $\mathrm{Na}_{x} \mathrm{WO}_{3}$. As the $x$ increases from 0 to 1 , the color of $\mathrm{Na}_{x} \mathrm{WO}_{3}$ gradually changes from lime green to dark blue, violet, pink, orange and yellow [10]. This change in color can be attributed to increase of bulk plasma frequency $\left(\omega_{\mathrm{p}}\right)$ [6]. Unlike other metals, the $\omega_{\mathrm{p}}$ of $\mathrm{Na}_{x} \mathrm{WO}_{3}$ can be tuned by Na content in $\mathrm{WO}_{3}[11,12]$.

In our previous work, we found that extinction behavior in visible and NIR region of rare-earth hexaboride $\left(\mathrm{RB}_{6}\right)$ is directly correlated with its $\omega_{\mathrm{p}}$, and nanocrystalline $\mathrm{RB}_{6}$ shows tunable optical characteristic as an excellent transparent heat-shielding material [13]. Like $\mathrm{RB}_{6}$, nanocrystalline $\mathrm{M}_{x} \mathrm{WO}_{3}$ is also an excellent transparent heat-shielding material, and even has a wider absorption range in the NIR region than $\mathrm{LaB}_{6}$ [14]. Because of the tunable $\omega_{\mathrm{p}}$ characteristic of $\mathrm{Na}_{x} \mathrm{WO}_{3}$, we infer that the extinction in the visible and NIR region of nanocrystalline $\mathrm{Na}_{x} \mathrm{WO}_{3}$ is also tunable by different $\mathrm{Na}$ content. However, the current research on tungsten bronzes mainly focuses on its preparation methods or co-doping effect [5,15-18]; the tunable absorption behavior of nanocrystalline tungsten bronzes has very rarely been reported in the literature. In this paper, nanocrystalline $\mathrm{Na}_{x} \mathrm{WO}_{3}$ powders with different $x$ were synthesized by a solvothermal method and their optical properties were discussed. In order to more systematically study the optical properties of nanocrystalline $\mathrm{Na}_{x} \mathrm{WO}_{3}$, the discrete dipole approximation (DDA) method was also used to investigate the influence of different $x$, particle size and particle shape on its optical properties.

\section{Materials and Methods}

\subsection{Fabrication}

To fabricate $\mathrm{Na}_{x} \mathrm{WO}_{3}$ nanopowders, different amounts $(0.09 \mathrm{~g}, 0.27 \mathrm{~g}, 0.45 \mathrm{~g}$ and $0.63 \mathrm{~g}$, respectively) of $\mathrm{NaOH}$ particles (Tianjin Kemiou Chemical Reagent Co., Tianjin, China) were fully ground and added gradually into $150 \mathrm{~mL}$ benzyl alcohol, then mixed with $\mathrm{WCl}_{6}$ (Shanghai Macklin Biochemical Co., Ltd., Shanghai, China) by magnetic stirring to obtain a dark blue precursor solution. In the precursor solution, the concentration of $\mathrm{WCl}_{6}$ remained at $0.015 \mathrm{M}$. Subsequently, the precursor solution was transferred into Teflon-lined autoclave, and reacted at $200{ }^{\circ} \mathrm{C}$ for $4 \mathrm{~h}$. After natural cooling, the reactants were washed with pure water and ethanol several times, then centrifuged and dried in vacuum at $40{ }^{\circ} \mathrm{C}$ for $1 \mathrm{~h}$ to obtain blue powder of $\mathrm{Na}_{x} \mathrm{WO}_{3}$.

\subsection{Characterization}

The phase identification of the samples was analyzed by X-ray diffraction (XRD, Philips PW1830, Hohhot, Inner Mongolia, China) with Cu K $\alpha(\lambda=1.5406 \AA)$, at $30 \mathrm{kV}$ voltage with $30 \mathrm{~mA}$ current and scanning rate of $1^{\circ} / \mathrm{min}$. The sample morphology was examined by using a field emission scanning electron microscope (SEM, Gemini 300, Beijing, China) with an Energy Dispersive Spectrometer (EDS, Oxford X-Max, Beijing, China). The microstructure was further characterized by transmission electron microscopy (TEM, FEI Talos F200X, Beijing, China) with accelerating voltage of $200 \mathrm{kV}$. The valence state of elements was analyzed by X-ray photoelectron spectroscopy (XPS, Escalab 250Xi, Baotou, Inner Mongolia, China) using a monochromatic $\mathrm{Al} \mathrm{k} \alpha \mathrm{X}$-ray source. Optical measurements of samples were performed at room temperature by using ultraviolet-visible-near infrared spectrometer (UV-Vis, HITACHI UH4150, Baotou, Inner Mongolia, China). 


\subsection{Simulation Method}

Discrete dipole approximation method (DDA) was used to study the influence of different $x$, different size and different shape on the extinction behavior of $\mathrm{Na}_{x} \mathrm{WO}_{3}$ nanoparticles. DDA is a method to calculate the far-field and near-field optical properties of nanostructures (usually called "target") with a variety of shapes and sizes, which adopts a finite array of dipoles to approximate the continuous material. The dipoles polarize under the action of light field and interact with each other through electric field. The absorption and scattering of materials can be obtained by calculating the polarization of the dipoles. Our previous work has proved that DDA method has strong advantages in calculation of transparent heat-shielding materials [19].

In the present work, DDSCAT7.3 software was used to simulate all the DDA results. DDSCAT7.3 is an open source fortran-90 program developed by Drain and Flatau of Princeton University to calculate the scattering and absorption of electromagnetic waves by particles with various geometric shapes and complex refractive indexes $[20,21]$. The extinction efficiency of target can be expressed as

$$
Q_{e x t}=\frac{C_{e x t}}{\pi a_{e f f}^{2}}
$$

where $C_{\text {ext }}$ is the extinction cross section and $a_{\text {eff }}$ is the effective radius (a radius of an equal volume sphere) of target. The complex dielectric constant of $\mathrm{Na}_{x} \mathrm{WO}_{3}$ measured by Owen et al. was used to calculate the extinction efficiency in this work [22].

\section{Results and Discussion}

To obtain a nanocrystalline $\mathrm{Na}_{x} \mathrm{WO}_{3}$ with different $x$ value, we mixed precursor solutions with different molar ratio of $\mathrm{Na} / \mathrm{W}$, as shown in Figure 1 . After magnetic stirring at $30 \mathrm{~min}$, the solution with $\mathrm{Na} / \mathrm{W}$ molar ratio of 1:1, 3:1 and 5:1 turned dark blue, but the solution with molar ratio of 7:1 was always kept at yellowish. After treatment in the reactor, blue powder was obtained from the solution with $\mathrm{Na} / \mathrm{W}$ molar ratio of 1:1, 3:1 and 5:1, but no solid precipitate was formed in the solution with $\mathrm{Na} / \mathrm{W}$ molar ratio of 7:1. We infer that tungsten trioxide reacted with $\mathrm{NaOH}$ and formed sodium tungstate when $\mathrm{NaOH}$ was excessive, so other methods are needed to obtain nanosized $\mathrm{Na}_{x} \mathrm{WO}_{3}$ with high $x$ value.

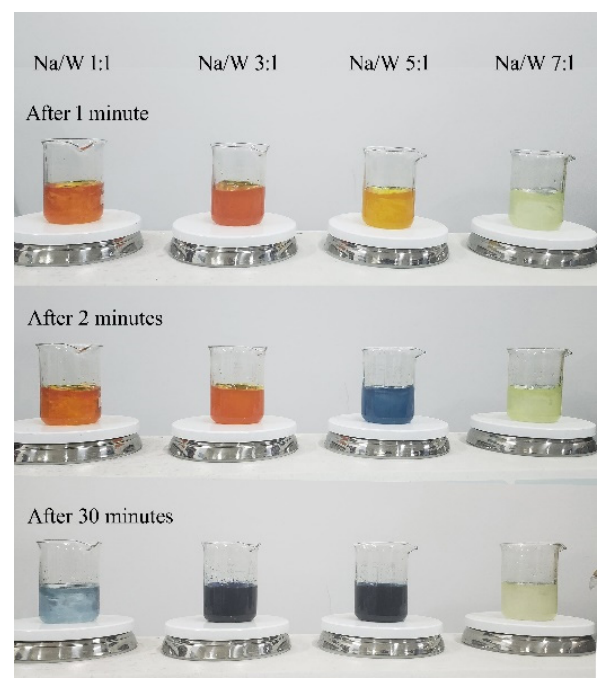

Figure 1. As-prepared precursor solutions with different molar ratio of $\mathrm{Na} / \mathrm{W}$ after different times.

Figure 2 shows the XRD results of three kinds of $\mathrm{Na}_{x} \mathrm{WO}_{3}$ nanopowders obtained from the solvothermal reaction. The sharp and intensive $X R D$ reflections indicate the wellcrystallized character of the samples. The XRD pattern of sample with $\mathrm{Na} / \mathrm{W}$ molar ratio of 1:1 can be indexed on the basis of a hexagonal phase of $\mathrm{Na}-\mathrm{WO}_{3}$ (JCPDS 81-0577). With 
increasing Na content, the peaks of (001) and (002) become stronger and all other peaks become weaker. The peaks of (001) and (002) also correspond to a cubic phase of $\mathrm{Na}^{-\mathrm{WO}_{3}}$ (JCPDS 28-1156). In addition, it can be seen from the partial enlarged view that the (001) peak slightly moves to higher angle with the increase of $\mathrm{Na}$ content, which corresponds to the position of the peak near $23^{\circ}$ on the JCPDS 81-0577 and JCPDS 28-1156. Therefore, we infer that the sample exhibits a tendency to change to cubic phase with increasing $\mathrm{Na}$ content. According to literature, the $\mathrm{Na}_{x} \mathrm{WO}_{3}$ shows a perovskite-type crystal structure with cubic symmetry at $x>\sim 0.4[6,7]$, which is consistent with our XRD results.
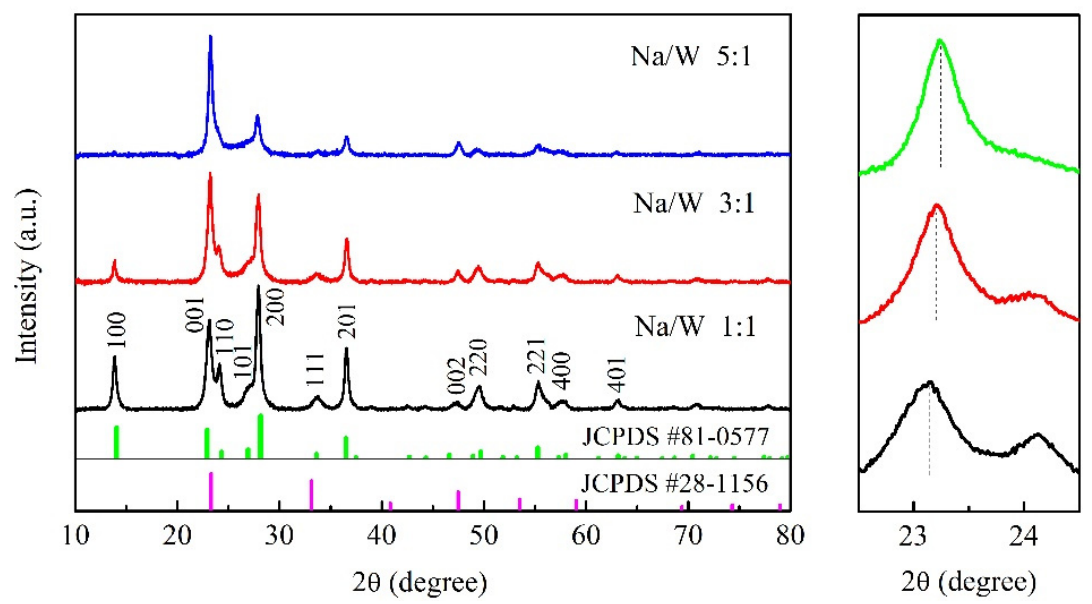

Figure 2. XRD patterns of the obtained powders (left) and partial enlarged view (right).

The SEM images of the synthesized $\mathrm{Na}_{x} \mathrm{WO}_{3}$ powders with different $\mathrm{Na} / \mathrm{W}$ ratios are shown in Figure 3. It can be seen from Figure 3a-c that all three samples are mainly composed of homogeneous and well-dispersed nanoparticles with sizes of several tens of nanometers. The EDS images in Figure $3 \mathrm{~d}-\mathrm{f}$ gives that the atomic ratios of $\mathrm{Na} / \mathrm{W}$ for three samples are $0.077,0.173$ and 0.243 , respectively. Figure $3 g-i$ show the element mapping of sample with $\mathrm{Na} / \mathrm{W}$ ratio of 1:1, which confirms the presence and uniform distribution of $\mathrm{O}, \mathrm{W}$ and $\mathrm{Na}$ in selected area.

To further study the detailed microstructure of obtained products, TEM was used to observe the grain morphology and crystallinity of the sample with $\mathrm{Na} / \mathrm{W}$ molar ratio of $1: 1$, and results are given in Figure 4. It can be seen from the TEM image that the sample is composed of nanoparticles with sizes of several tens of nanometers, which is consistent with the results of SEM. Moreover, two kinds of crystalline lattice constant in the HRTEM images were calculated as 0.389 and $0.638 \mathrm{~nm}$, which agrees well with the interplanar spacing $\left(\begin{array}{lll}0 & 0 & 1\end{array}\right)$ and (100) of the hexagonal phase of $\mathrm{Na}-\mathrm{WO}_{3}$ (JCPDS 81-0577), respectively.

The chemical state of the $\mathrm{Na}_{x} \mathrm{WO}_{3}$ nanoparticles was carefully determined by XPS. Figure 5 shows the typical XPS of the tungsten core level $\left(\mathrm{W}_{4 \mathrm{f}}\right)$ in the $\mathrm{Na}_{x} \mathrm{WO}_{3}$ nanoparticles with $\mathrm{Na} / \mathrm{W}$ ratio of 1:1. The spectrum can be fitted to two groups of spin-orbit doublets of $W_{4 f 7 / 2}$ and $W_{4 f 5 / 2}$ with a separation distance of $2.1 \mathrm{eV}$, indicating two different oxidation states of $\mathrm{W}$ element. The peaks at 37.6 and $35.5 \mathrm{eV}$ can be attributed to the $\mathrm{W}$ element being in a $6+$ oxidation state, while 36.5 and $34.4 \mathrm{eV}$ can be assigned to the $\mathrm{W}$ element being in a $5+$ oxidation state. It is suggested that the typical nature of non-stoichiometric tungsten bronzes can be expressed as the formula of $\mathrm{M}_{x} \mathrm{~W}^{6+}{ }_{1-x} \mathrm{~W}^{5+}{ }_{x} \mathrm{WO}_{3}$; our XPS results are in good agreement with this reduced feature. Na atoms can contribute a number of free electrons when they are doped into the structure of $\mathrm{WO}_{3}$, and part of the $\mathrm{W}^{6+}$ will be reduced to $\mathrm{W}^{5+}$. The transparent heat-shielding properties of tungsten bronzes are closely related to the plasmon resonance of free electrons, and the concentration of free electrons has a great influence on the $\omega_{\mathrm{p}}$. Therefore, the transparent heat-shielding properties of tungsten bronzes could be tuned by controlling the concentration of free electrons in its microstructure. 

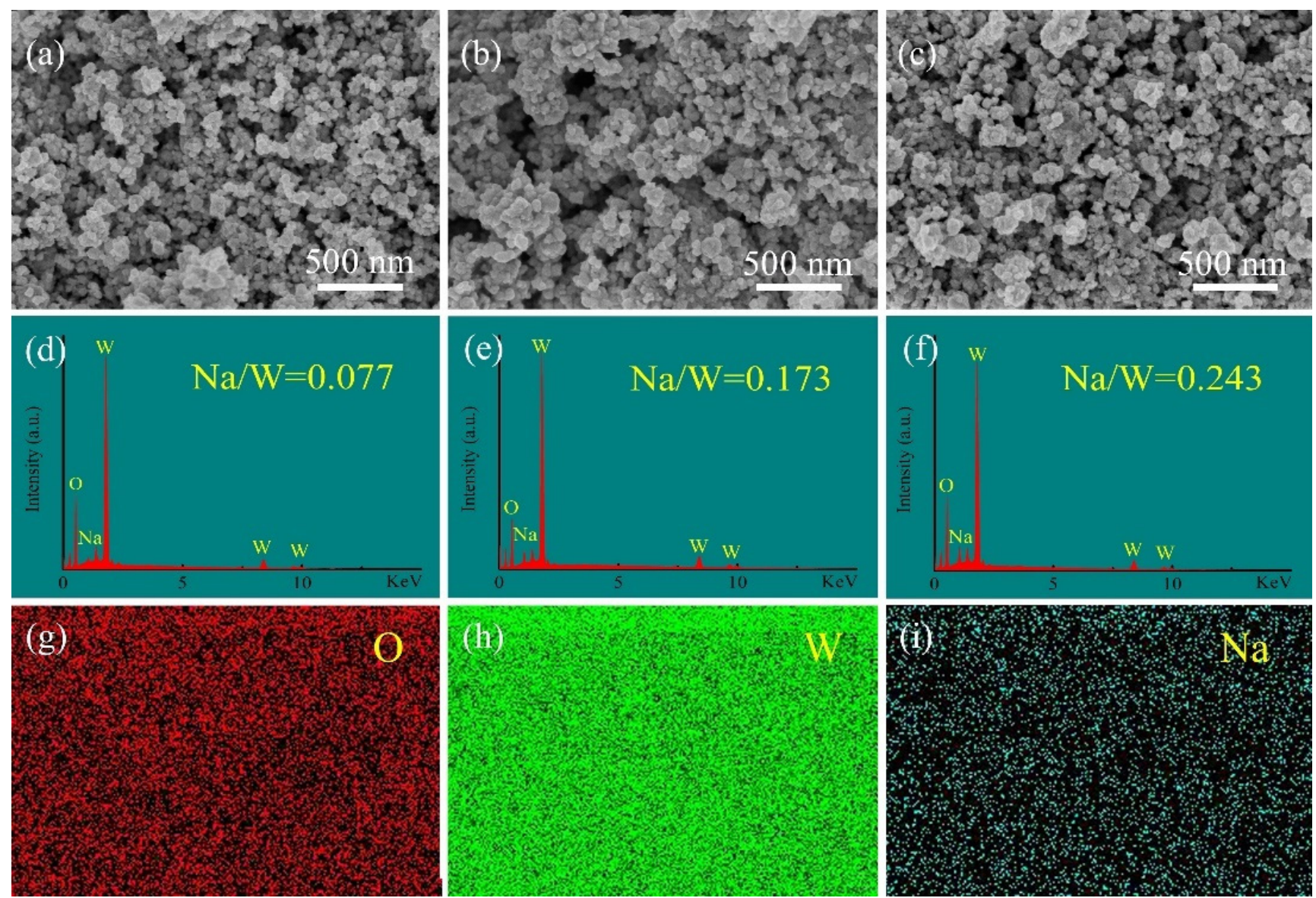

Figure 3. SEM images of $\mathrm{Na}_{x} \mathrm{WO}_{3}$ synthesized with the $\mathrm{Na} / \mathrm{W}$ ratio of (a) 1:1, (b) 3:1, (c) 5:1; corresponding EDS images (d) 1:1, (e) 3:1, (f) 5:1; element mapping of sample with Na/W ratio of 1:1 (g) O, (h) W, (i) Na.

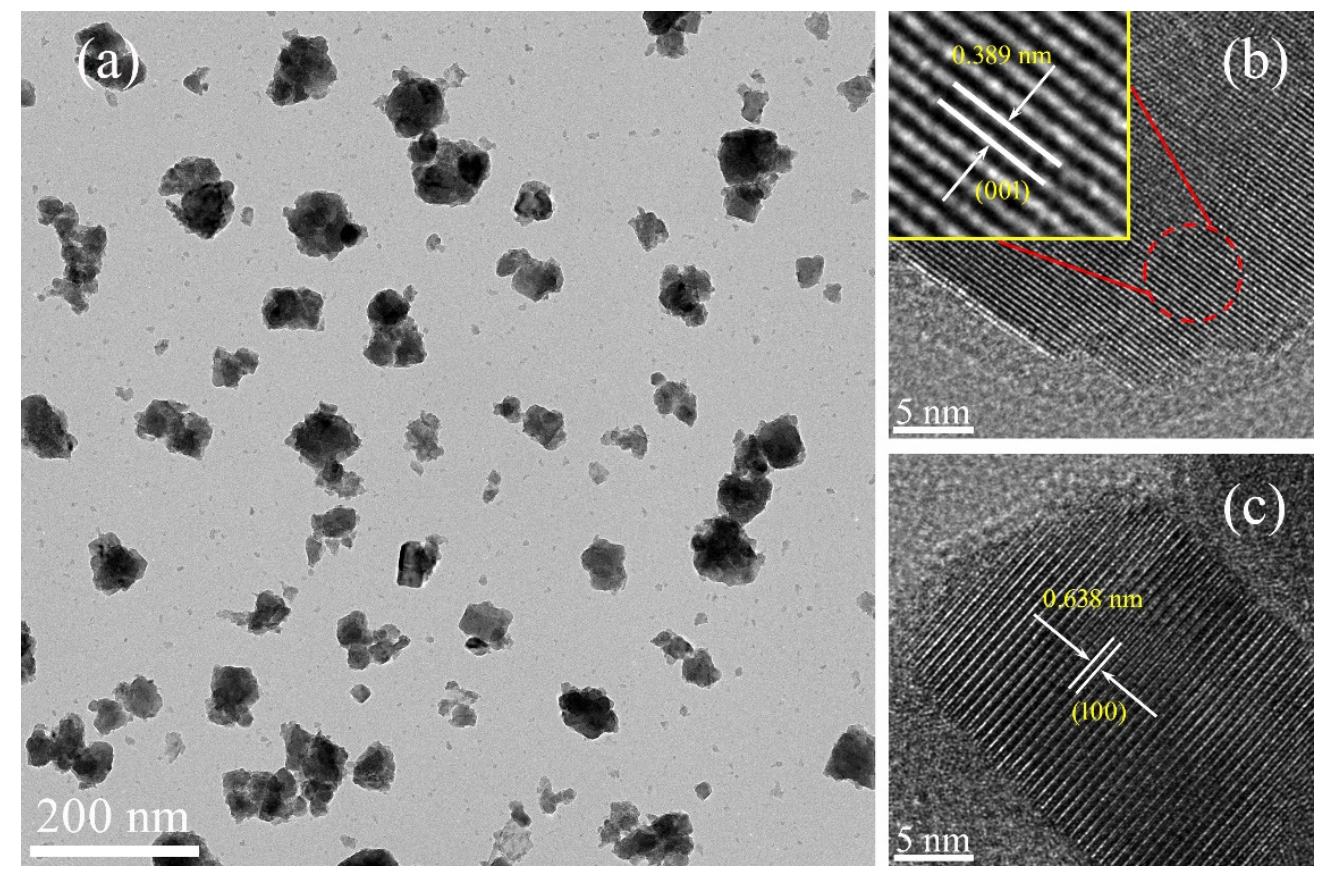

Figure 4. TEM image (a) and HRTEM images $(\mathbf{b}, \mathbf{c})$ of the $\mathrm{Na}_{x} \mathrm{WO}_{3}$ nanoparticles with $\mathrm{Na} / \mathrm{W}$ ratio of 1:1. 


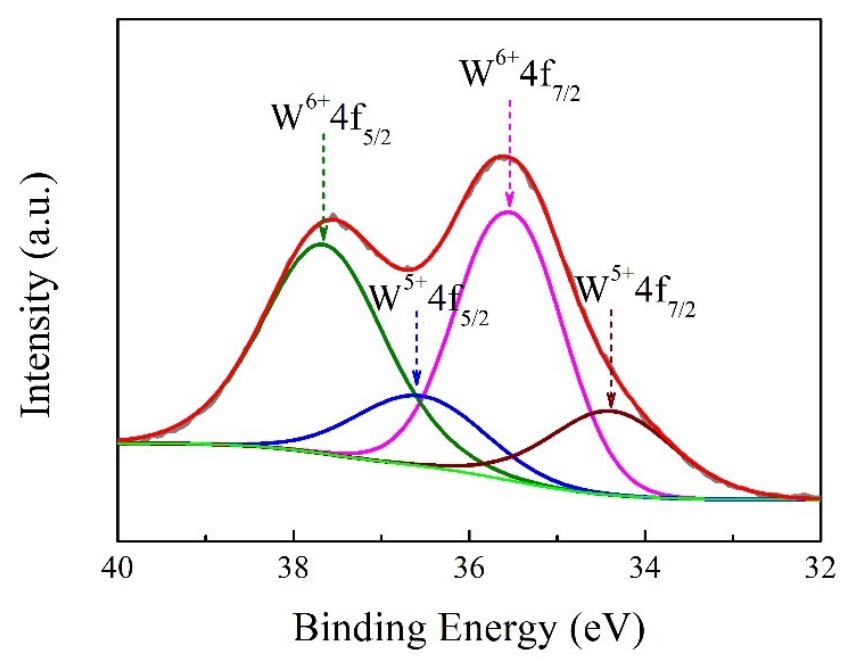

Figure 5. Tungsten core-level $\left(\mathrm{W}_{4 \mathrm{f}}\right)$ XPS spectra of the $\mathrm{Na}_{x} \mathrm{WO}_{3}$ nanoparticles with $\mathrm{Na} / \mathrm{W}$ ratio of 1:1.

To investigate the optical properties of $\mathrm{Na}_{x} \mathrm{WO}_{3}$, the same amount of obtained powder sample was uniformly dispersed and coated on the glass slide, and the absorption spectra are shown in Figure 6. All three samples exhibit low and high absorption characteristics in the visible and NIR region, respectively. The absorption valley occurs at $555 \mathrm{~nm}$ for the sample with $\mathrm{Na} / \mathrm{W}$ ratio of 1:1, and shifts to shorter wavelength of $514 \mathrm{~nm}$ for the sample with $\mathrm{Na} / \mathrm{W}$ ratio of 5:1. The corresponding absorption peak in NIR region shows the same trend as the absorption valley, with shifts from $1733 \mathrm{~nm}$ to $1498 \mathrm{~nm}$. These results illustrate that the transparency in visible and NIR region of nanocrystalline $\mathrm{Na}_{x} \mathrm{WO}_{3}$ can be effectively tuned by $x$ content. Generally, the low optical absorption in visible region can be ascribed to the $\omega_{\mathrm{p}}$, which corresponds to the peak in low energy region of energy loss spectra. The electron energy loss spectra for $\mathrm{Na}_{x} \mathrm{WO}_{3}$ with different $x$ value have been measured by Tegg et al. [12], and results showed that the position of peak in low energy region shifts to higher energy as $x$ increases, which is consistent with our results in Figure 6.
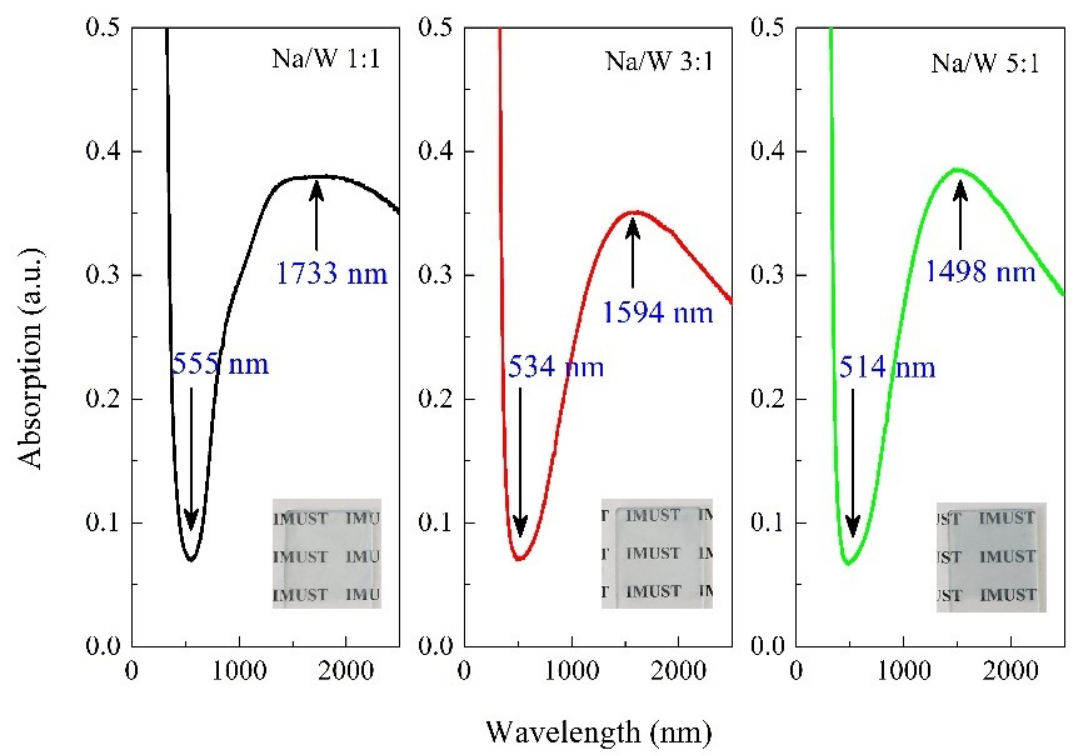

Figure 6. Absorption spectra of $\mathrm{Na}_{x} \mathrm{WO}_{3}$ nanoparticles with $\mathrm{Na} / \mathrm{W}$ ratio of 1:1, 3:1 and 5:1. Inset shows the photograph of the thin film samples used in the test.

However, the nanoparticulated $\mathrm{Na}_{x} \mathrm{WO}_{3}$ with higher $x$ values could not be synthesized in our experiment. Therefore, the optical properties of nanosized $\mathrm{Na}_{x} \mathrm{WO}_{3}$ with higher 
$x$ values in the visible and NIR region were calculated theoretically by using the DDA method. The DDA simulation gives the extinction efficiencies $\left(Q_{e x t}\right)$ of single particle. In order to compare simulation results with the experiment, we plotted $Q_{\text {ext }} / a_{\text {eff }}$ [23]. It should be noted that the absorption curve measured by UV-Vis spectrophotometer is converted from the transmittance of the sample, so the absorption spectrum from our measurement corresponds to the extinction curve from DDA calculations. Figure 7 gives the extinction curves of sphere-shaped $\mathrm{Na}_{x} \mathrm{WO}_{3}$ particles with size of $50 \mathrm{~nm}$ and $x$ value of $0.522,0.628$, $0.695,0.740,0.860$ and 0.940 . For $x=0.522$, the extinction valley occurs at $501 \mathrm{~nm}$ and gradually shifts to $423 \mathrm{~nm}$ for $x=0.94$ with increasing $\mathrm{x}$, which is in good agreement with our experimental results. Combining the experimental results with the DDA simulation results, it can be found that the position of the transmission peak of $\mathrm{Na}_{x} \mathrm{WO}_{3}$ in the visible region can be continuously adjusted by $x$ value in the whole range of $0<x<1$. In addition, the extinction peak position shifts from $749 \mathrm{~nm}$ to $640 \mathrm{~nm}$ when $x$ increases from 0.522 to 0.94. Although the shifting trend with $x$ value is the same as that in Figure 6 , the position of extinction peak is much smaller than that in Figure 6. The reason for this difference should be related to the size and shape of nanoparticles. The experimental sample is composed of particles of various sizes and shapes, and the measured absorption spectrum is the comprehensive effect of all particles. However, what DDA calculates is particles with size of $50 \mathrm{~nm}$ and shape of ideal sphere. In order to verify this inference, we also calculated the extinction behavior of $\mathrm{Na}_{x} \mathrm{WO}_{3}$ particles of different sizes and shapes.

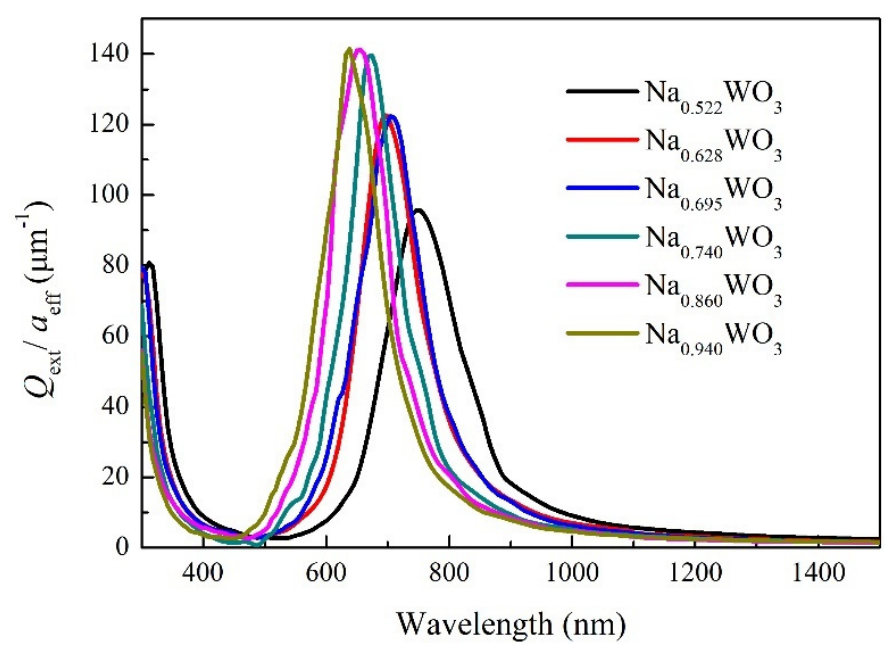

Figure 7. Extinction curves of sphere-shaped $\mathrm{Na}_{x} \mathrm{WO}_{3}$ particles with size of $50 \mathrm{~nm}$ and different $x$ value.

The calculated extinction curves of spherical-shaped $\mathrm{Na}_{0.522} \mathrm{WO}_{3}$ particles with different sizes and differently shaped $\mathrm{Na}_{0.522} \mathrm{WO}_{3}$ particles with size of $50 \mathrm{~nm}$ are given in Figure 8. It can be found that there was significant difference between the extinction curves of different-sized particles. The extinction valley shifts toward short wavelength direction and broadens with the decreasing particle size. While the extinction peak broadens and shifts to long wavelength direction with the increasing particle size, the peak intensity weakens. For different shapes, there is little difference in the shape and position of the extinction valley, while the intensity, width and position of extinction peak are very different. Generally, a strong absorption or scattering effect occurs when the collective oscillation frequency of the conduction electrons is the same as that of the incident photons, which leads to an enhancement of the electromagnetic field in a very small area of the particle surface. On the other hand, the charge distribution produced by collective oscillation of particles with different shapes is also different; our calculated electric field distribution around the variously shaped $\mathrm{Na}_{x} \mathrm{WO}_{3}$ particles is shown in Figure 9 (all simulations assume that the incident light propagates along the $\mathrm{x}$-axis.). This suggests that the localized surface plasmon resonance (LSPR) is highly sensitive to different symmetries and angles. 
Therefore, the extinction behavior of particles with different shapes is quite different in the near infrared region. From the simulation results of particles with different sizes and shapes, it can be concluded that the wide range absorption in the NIR region in the experiment is a common effect of various sizes and shapes of $\mathrm{Na}_{x} \mathrm{WO}_{3}$ particles.
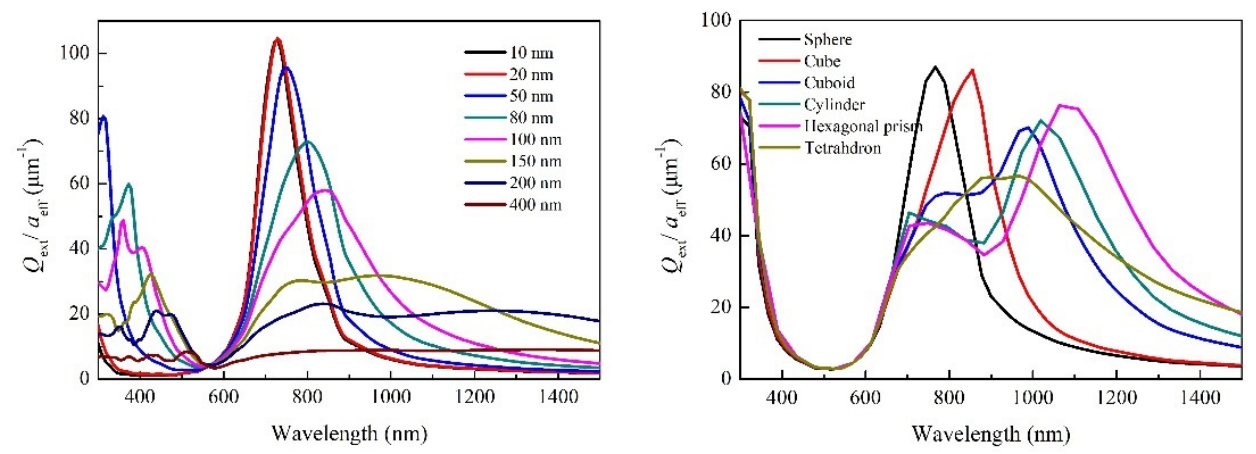

Figure 8. Extinction curves of spherical-shaped $\mathrm{Na}_{0.522} \mathrm{WO}_{3}$ particles with different sizes (left) and differently shaped $\mathrm{Na}_{0.522} \mathrm{WO}_{3}$ particles with size of $50 \mathrm{~nm}$ (right).

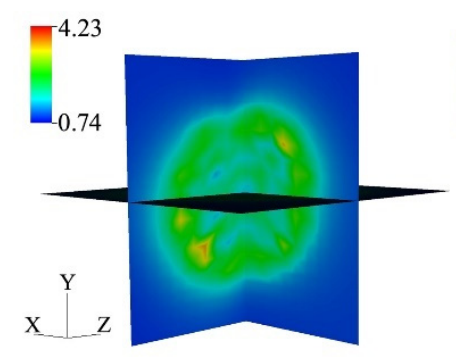

Sphere: $766 \mathrm{~nm}$

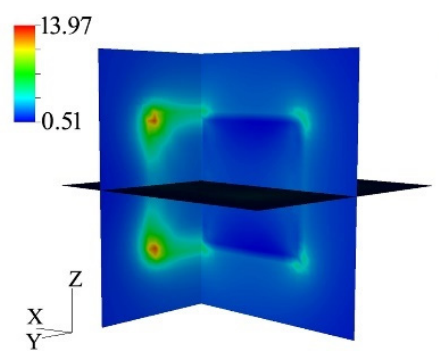

Cube: $852 \mathrm{~nm}$

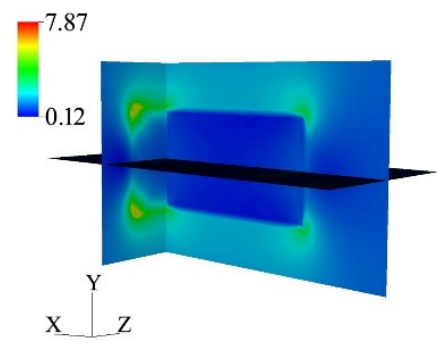

Cuboid: $988 \mathrm{~nm}$
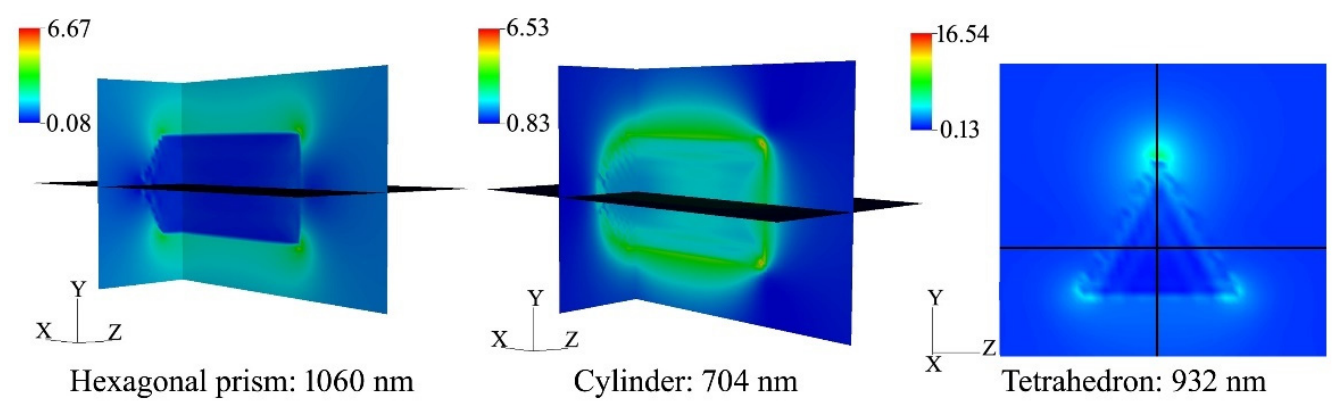

Tetrahedron: $932 \mathrm{~nm}$

Figure 9. Electric field distribution around the variously shaped $\mathrm{Na}_{0.522} \mathrm{WO}_{3}$ particles with effective radius of $50 \mathrm{~nm}$ at their corresponding plasma resonance peaks.

\section{Conclusions}

The optical properties of nanoparticulated $\mathrm{Na}_{x} \mathrm{WO}_{3}$ with different $x$ have been both experimentally and theoretically investigated in this paper. The EDS results showed that the atomic ratios of $\mathrm{Na} / \mathrm{W}$ for three samples are $0.077,0.173$ and 0.243 , indicating that $x$ is gradually increasing in the synthesized samples. Absorption measurement showed that the absorption valley in visible region shifts from $555 \mathrm{~nm}$ to $514 \mathrm{~nm}$ when Na/W ratio changes from 1:1 to 5:1, and the corresponding absorption peak in NIR region shifts from $1733 \mathrm{~nm}$ to $1498 \mathrm{~nm}$. These show that the absorption (or transmittance) behavior in visible and NIR region of nanocrystalline $\mathrm{Na}_{x} \mathrm{WO}_{3}$ can be effectively tuned by $x$ content. The subsequent DDA simulation results show that this tunable characteristic is also suitable for the nanoparticulated $\mathrm{Na}_{x} \mathrm{WO}_{3}$ with higher $x$ values. The continuously tunable optical properties of nanocrystalline $\mathrm{Na}_{x} \mathrm{WO}_{3}$ make it very promising in the fields of transparent heat-shielding materials or optical filters. 
Author Contributions: Conceptualization, supervision and writing-original draft, L.C.; investigation, methodology and software, C.S.; data curation, J.D.; visualization, J.L. (Jiaxin Li); validation, J.L. (Jia Liu); resources and formal analysis, Y.M.; writing-review and editing and funding acquisition, L.X. All authors have read and agreed to the published version of the manuscript.

Funding: This research was funded by the National Natural Science Foundation of China (Grant No. 51776046), the Natural Science Foundation of Inner Mongolia (Grant No.2019MS05015), the Innovation Fund of Inner Mongolia University of Science and Technology (Grant No. 2019QDL-B35), the Guizhou Provincial Science and Technology Foundation (20191133) and the Youth Science and Technology Talent Development Fund in Guizhou Provincial Department of Education (2018250).

Data Availability Statement: The data presented in this study are available on request from the corresponding author.

Conflicts of Interest: The authors declare no conflict of interest.

\section{References}

1. Garif'yanov, N.N.; Khlebnikov, S.Y.; Khlebnikov, I.S.; Garifullin, I.A. Superconductivity of sodium tungsten bronze with cubic structure. Czechoslov. J. Phys. 1996, 46, 855-856. [CrossRef]

2. Gao, T.; Jelle, B.P. Visible-light-driven photochromism of hexagonal sodium tungsten bronze nanorods. J. Phys. Chem. C 2013, 117, 13753-13761. [CrossRef]

3. Gao, T.; Jelle, B.P. Electrochromism of hexagonal sodium tungsten bronze nanorods. Sol. Energy Mater. Sol. Cells 2018, 177, 3-8. [CrossRef]

4. Liu, G.; Wang, S.; Nie, Y.; Sun, X.; Zhang, Y.; Tang, Y. Electrostatic-induced synthesis of tungsten bronze nanostructures with excellent photo-to-thermal conversion behavior. J. Mater. Chem. A 2013, 1, 10120. [CrossRef]

5. Chao, L.M.; Bao, L.H.; Wei, W.; Tegus, O. A review of recent advances in synthesis, characterization and NIR shielding property of nanocrystalline rare-earth hexaborides and tungsten bronzes. Sol. Energy 2019, 190, 10-27. [CrossRef]

6. Raj, S.; Matsui, H.; Souma, S.; Sato, T.; Takahashi, T.; Chakraborty, A.; Sarma, D.D.; Mahadevan, P.; Oishi, S.; McCarroll, W.H.; et al. Electronic structure of sodium tungsten bronzes $\mathrm{Na}_{x} \mathrm{WO}_{3}$ by high-resolution angle-resolved photoemission spectroscopy. Phys. Rev. B 2007, 75, 155116. [CrossRef]

7. Shanks, H.R. Growth of tungsten bronze crystals by fused salt electrolysis. J. Cryst. Growth 1972, 13-14, 433-437. [CrossRef]

8. Zhong, Q.; Dahn, J.R.; Colbow, K. Lithium intercalation into $\mathrm{WO}_{3}$ and the phase diagram of $\mathrm{Li}_{\mathrm{x}} \mathrm{WO}_{3}$. Phys. Rev. B 1992, 46, 2554-2560. [CrossRef] [PubMed]

9. Sayed, A.M.E.; Mousa, S.M.A. Some properties of sodium tungsten bronzes as a function of sodium concentration. Indian J. Chem. Technol. 2005, 12, 304-308.

10. Bevan, D.J.M.; Hagenmuller, P. Nonstoichiometric Compounds: Tungsten Bronzes, Vanadium Bronzes and Related Compounds; Pergamon Press: Oxford, UK, 1975.

11. Tegg, L.; Cuskelly, D.; Keast, V.J. The sodium tungsten bronzes as plasmonic materials: Fabrication, calculation and characterization. Mater. Res. Express 2017, 4, 065703. [CrossRef]

12. Tegg, L.; Cuskelly, D.; Keast, V.J. Plasmon responses in the sodium tungsten bronzes. Plasmonics 2017, 13, 437-444. [CrossRef]

13. Chao, L.M.; Bao, L.H.; Shi, J.; Wei, W.; Tegus, O.; Zhang, Z.D. The effect of Sm-doping on optical properties of LaB 6 nanoparticles. J. Alloy Compd. 2015, 622, 618-621. [CrossRef]

14. Xin, Y.; Cao, X.; Bao, S.; Ji, S.; Li, R.; Yang, Y.; Zhou, H.; Jin, P. Two-step fabrication of $\mathrm{Na}_{x} \mathrm{WO}_{3}$ thin film via oxygen-vacancyinduced effect for energy efficient applications. CrystEngComm 2017, 19, 3931-3938. [CrossRef]

15. Wu, P.J.; Brahma, S.; Lu, H.H.; Huang, J.L. Synthesis of cesium tungsten bronze by a solution-based chemical route and the NIR shielding properties of cesium tungsten bronze thin films. Appl. Phys. A 2020, 126, 98. [CrossRef]

16. Tu, H.; Wang, W.; Chen, D.R. Aerosol-assisted production of NIR shielding nanoparticles: Sodium tungsten bronze. Aerosol Air Qual. Res. 2020, 20, 690-701. [CrossRef]

17. Yao, Y.; Zhang, L.; Chen, Z.; Cao, C.; Gao, Y.; Luo, H. Synthesis of $\mathrm{Cs}_{\mathrm{x}} \mathrm{WO}_{3}$ nanoparticles and their NIR shielding properties. Ceram. Int. 2018, 44, 13469-13475. [CrossRef]

18. Yang, J.; Liu, J.; Shi, F.; Ran, S.; Liu, S. Tm, Yb co-doped urchin-like $\mathrm{Cs}_{\mathrm{x}} \mathrm{WO}_{3}$ nanoclusters with dual functional properties: Transparent heat insulation performance and enhanced photocatalysis. Ceram. Int. 2021, 47, 8345-8356. [CrossRef]

19. Sun, C.W.; Liu, J.; Chao, L.M. Theoretical analysis on optical properties of $\mathrm{Cs}_{0.33} \mathrm{WO}_{3}$ nanoparticles with different sizes, shapes and structures. Mater. Lett. 2020, 272, 127847. [CrossRef]

20. Draine, B.T.; Flatau, P.J. User Guide for the Discrete Dipole Approximation Code DDSCAT 7.3. arXiv 2013, arXiv:1305.6497.

21. Heide, P.A.M.; Cate, H.W.; Dam, L.M.; Groot, R.A.; Vroomen, A.R. Differences between LaB6 and CeB6 by means of spectroscopic ellipsometry. J. Phys. F Met. Phys. 1986, 16, 1617-1623. [CrossRef] 
22. Owen, J.F.; Teegarden, K.J.; Shanks, H.R. Optical properties of the sodium-tungsten bronzes and tungsten trioxide. Phys. Rev. B 1978, 18, 3827-3837. [CrossRef]

23. Adachi, K.; Miratsu, M.; Asahi, T. Absorption and scattering of near-infrared light by dispersed lanthanum hexaboride nanoparticles for solar control filters. J. Mater. Res. 2010, 25, 510-521. [CrossRef] 